\title{
Technical Analysis of Lightning Protection System in Urban Railway Transit
}

\author{
Qiaoling Tang \\ Shandong Technical Center of Lightning Protection, Jinan Shandong, China \\ tangqiaoling7305@163.com
}

Keywords: Railway transit; Lightning protection system; Lightning equipotential bonding

\begin{abstract}
The subways are engineering construction projects with highly centralized mechatronic, electrical and electronic systems, which are vulnerable to be attacked by lightning, and causing personal injuries and economic losses. Through calculating of the number of the predicted lightning strikes in Jinan, the significance of the railway transit in city is analyzed, the results indicate that the railway stations are determined as the second type of buildings for lightning protection. According to the classification of the traction power supply, the protection method of direct lightning of the overhead contact line equipment and the contact rail are discussed respectively. The reasons of both grounding and insulation installation are analyzed about platform screen door system, and the measures for insulation installation of platform screen door system are given, that provide a basis for the detection of railway transit lightning protection devices.
\end{abstract}

\section{Introduction}

Urban railway transit is a fast, large or medium volume of trains driven by electric in the city. Trains run on all closed lines, and the lines can be laid in the underground, on the ground or on the elevated ground[1]. Now the urban rail transit is a highly centralized project construction project of mechanical and electrical systems and electronic systems, lightning directly threaten the personal safety of passengers and related personnel, resulting dysfunction or failure in signals, communications systems and electronic and electrical system such as traction power supply. July 22, 2010 evening, lightning struck the south extension line of Nanjing Metro Line 1, resulting in two failures on power supply contact network, and 4 trains delayed owing to catenary outages, more than 2000 passengers travel affected by varying degrees. So it is necessary to study the lightning protection technology of railway transit.

\section{Determination of Lightning Protection Class for Station}

Number of Lightning Strikes per Annum. Rail transport is not limited to the line in the underground tunnel, it refers to the high specifications electric passenger train in peak hour one-way transportation capacity of 3 million to 7 million people in the large capacity of urban rail traffic system at the same time, with a variety of lines, underground, ground, elevated three characteristics of the combination of organic.

The length of the subway station is generally $120 \sim 150 \mathrm{~m}$, width $20 \sim 45 \mathrm{~m}$, high $15 \sim 20 \mathrm{~m}$ [2]. The number of the predicted lightning strikes in station buildings per annum [3] is

$$
N=k \times N g \times A e
$$

where $N$ is the number of the building is expected to be struck per annum(f/a); $k$ is the correction factor, depending on the location of the station and the surrounding environment, the $k$ values are 1 (urban), 1.5 (by the river, and groundwater outcrop) or 2 (in the isolated area); $N g$ is the annual average density of lightning strike in the area of the building $\left(\mathrm{f} /\left(\mathrm{km}^{2} \cdot \mathrm{a}\right)\right) ; A e$ is the equivalent area of the building with the same number of lightning strike $\left(\mathrm{km}^{2}\right)$.

$$
N g=0.1 \times T d
$$


Td is the average annual thunderstorm days(d/a), according to the local weather station data. The latest data of annual average thunderstorm days in Jinan area is 24.2 days. After calculation, the average annual lightning strike times of station buildings are $0.06 \sim 0.2$ (f/a).

Importance Analysis. According to the provisions of the national laws [4] and related standards [5], within the same time aggregation number more than 50 people in public places the construction set for personnel intensive place public buildings, crowded places including passenger station, passenger terminal, a civil airport waiting, waiting for ships, lounge (floor). Therefore, the subway station belongs to a crowded place. According to the Shandong region in summer lightning activity and temporal and spatial characteristics analysis [6], in the thunderstorm season 18:00 - 19:00 to lightning peak periods, and positive school and evening peak commuting time, Jinan City road traffic pressure. The station once the occurrence of lightning events, to a lesser extent affect people's travel and life, the person that weigh on the station staff, especially of pose a threat to the personal safety of the passengers on the platform and the personnel intensive will lead to expansion of the threat and damage range, extremely serious consequences.

According to the code for design of building lightning protection GB50057-2010 the 3.0.3 in the paragraph 9: "the expected lightning frequency is greater than 0.05 (f/a) ministerial and provincial office buildings and other important or personnel intensive public buildings and fire hazardous location" should be identified as the second type of buildings for lightning protection, considering the importance of subway station, the use of nature, lightning likelihood and consequence, combined with subway station is expected in the number of lightning, station buildings should be defined as the second type of buildings for lightning protection, and should be in accordance with the relevant requirements of building integrated lightning protection design.

\section{Lightning Protection of Traction Power Supply}

Traction network is a general term for the circulation loop of the power supply and the power supply of the electric locomotive, which is composed of the contact network and the return flow network. The contact network is a positive electrode, and the back flow network is a negative electrode, and is connected with the traction substation through the Internet cable and the return cable. The contact network is divided into the contact rail and the overhead contact network according to the different installation position and the contact wire. The contact rail and the flexible overhead contact net can be applied to the ground, the ground line and the overhead line. Following the lightning protection method of traction power supply on the ground to discuss.

Overhead Contact Line. The overhead contact line is at the end of the tunnel, the power supply isolation switch for the ground contact network, the open ground section and the viaduct section shall be provided with lightning arrester at every $500 \mathrm{~m}$. In the ground segment and viaduct section, the overhead catenary overhead ground wire should be every $200 \mathrm{~m}$ is provided with a spark gap, when the conditions are satisfied, overhead ground wire can also doubles as a lightning conductor. The power frequency grounding resistance of arrester and spark gap should not be more than $10 \Omega$.

Contact Rail. Usually, the subway train running in the open area is in the highest position. According to the principle of lightning discharge analysis, it is known that the running of the train is vulnerable to the object of the lightning strike, the metal body at the top of the train, especially the air conditioning equipment; the shell may become the first choice of lightning discharge. The contact rail feeding mode of the subway train, considering the width of the interval train, the train's height and other factors, setting a certain height and good grounding poles as lightning arrester, lightning protection problem for train. The protective height can be calculated as follows:

$$
h x=h r-\sqrt{(h r-h)^{2}+\left(\frac{D}{2}\right)^{2}-x^{2}}
$$

Where $h x$ is pole protection height $(\mathrm{m}) ; h r$ is ball radius, $45 \mathrm{~m} ; h$ is the height of pole relative to the rail surface $(\mathrm{m}) ; D$ is the pole spacing on both sides of elevated bridge $(\mathrm{m}) ; x$ is the horizontal distance of protected point to the midpoint of two poles $(\mathrm{m})$. 
In addition, properly thickened at the top of the train, especially air conditioning equipment housing alloy plate thickness, or at the top of the carriage are longitudinally arranged appropriate height of the metal belt lightning belt can be used, to prevent lightning strike directly on the roof and air-conditioning equipment, metal plate fusion hole, damage to the train.

\section{Lightning Protection of Subway Platform Screen Door}

Platform screen door (PSD) as an important part of the subway traffic facilities, but also the main channel for passengers to get off the main channel facilities, its security is particularly important. Shielding door is arranged on the edge of the platform of subway, the train and the platform waiting room isolation, not only can prevent passengers into the rail line area and there is danger, you can also reduce the platform area and the rail line between cold and hot air exchange and reduce environmental control and the operation energy consumption of the system, thus saving operating the $[8,9]$. Platform screen door is a typical mechanical and electrical integration device, because of its special installation position, when walking in the rail and near the station or subway station when it is affected by lightning; it is very easy to be affected. For lightning protection, shielding door system needs to take a series of lightning protection measures such as low impedance grounding, for personnel safety considerations, platform screen door also need to use high impedance insulation installation.

Subway trains generally use DC traction power supply system, the positive electrode is connected with the contact line, the line track and do the reflux channel connected to the substation. In order to reduce the influence of stray current on the track, the track structure should have good insulating property. So go between the track and ballast is lay insulation of, which will lead you down the rail line between the earth and forming a potential difference of the train body charged. Because of platform screen door is arranged on the edge of the platform, and train body, close to the rail line, stray current ideal diffusion channel and passengers get off easy access to screen door metal structure and the body itself caused by electric shock damage. In order to prevent stray current to prevent the contact voltage to the main structure of diffusion but also through the screen door, it must be shielding door insulation installation. The platform screen door unit door body should be electrically connected into a body of such potential, the transition resistance should be less than $0.4 \Omega$ and the insulation resistance between the door body and the structure of the station should not be less than $0.5 \mathrm{M} \Omega[10$, 11]. The platform screen door upper structure and indoor ceiling insulation, sealing.

In order to completely eliminate the platform screen door and go for the difference between the rail potential, must be shielding door and walk the line rail equipotential connection and take over voltage protection measures. Specific approach is the shielding door of each unit is composed of equipotential body and go on one side of the rail line is electrically connected, and then go rail line through the voltage limiter is connected to the substation ground bus. In the case of normal track potential, the potential limiter is always open to the track, and once the track potential exceeds the threshold value, the action of the potential limiter will be put into the track [12].

The platform screen door control room should be set grounding terminal and equipotential connection, and ensures the reliable connection and grounding station. All indoor equipment shall be equipotential connection, form the equipotential grounding network. As shown in Fig. 1. 


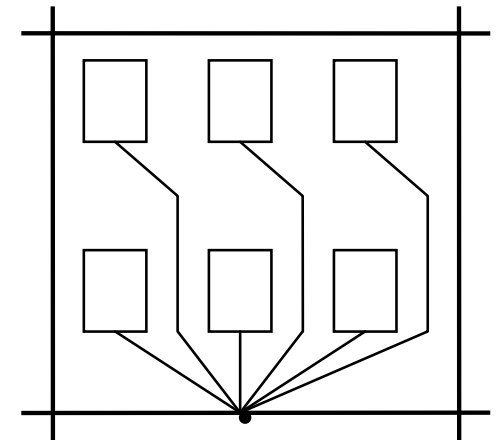

ERP

equipment



- equipotential connection point

Figure 1. Bonding network

\section{Summary}

Lightning protection is an important component part of the safe operation of the subway, the perfect subway lightning protection device design, it is necessary to accurately understanding, mastering and carry out the relevant existing lightning protection technology standard, more perfect urban rail transit lightning protection technology requirements as the design technical support, to ensure railway transportation safety and reliable operation.

\section{References}

[1] GB 50490-2009 Technical Code of Urban Rail Transit (China Architecture \& Building Press, China 2009). (In Chinese)

[2] P.J.Song, Y.Y.Wang: Lightning Protection Design of Elevated Subway Stations, Meteorological Science and Technology, Vol.41(2013)No.4,p.753-757. (In Chinese)

[3] GB50057-2010 Technical Specifications for Inspection of Lightning Protection System in Building (China Planning Press, China 2011). (In Chinese)

[4] Fire Control Law of the People's Republic of China (Law Press, China 2008). (In Chinese)

[5] GB50016-2006 Code for Fire Protection Design of Building (China Planning Press, China 2006). (In Chinese)

[6] Q.L.Tang, J.C.Sun and Y.C.Sun: Analysis of the Lightning Distribution and Lightning Strike Disaster Characteristics in Shandong Province, Modern Electronics Technique, Vol. 35 (2012) No.2,p.65-68. (In Chinese)

[7] GB50157-2003 Code for Design of Metro (China Planning Press, China 2003). (In Chinese)

[8] Z.H.Hu, X.F.Ye and W.Cai: Analysis of the Applicability of the Platform Screen Door in Urban Mass Transit, Urban Mass Transit, Vol.3(2002)No.1,p.17-19. (In Chinese)

[9] S.Z.Chen: Underground Railway Platform Screen Door System (Science Press, China 2005), p.17-23. (In Chinese)

[10] CJ/T 236-2006 Urban Railway Transportation Platform Screen Door System (Standards Press of China, China 2007). (In Chinese) 
[11] GB50382-2006 Code for Constructional Quality Acceptance of Urban Rail Transit Communication Engineerin (China Planning Press, China 2006). (In Chinese)

[12] J.W.Wu, J.W.Bu and B.Pan: Relevant Research on the Lightning Protection and Insulation of Metro PSD System, Plateau and Mountain Meteorology Research, Vol.33(2013)No.2,p.74-77. (In Chinese) 